\title{
Pendidikan Nasional \\ Memasuki Era Otonomi Daerah
}

\author{
Usman Abu Bakar
}

Misimplementation of autonomous region has caused education sector get a little part of local budget allocation. Meanwhile, local government has chances for improving human resources and industrialization.

\section{Dinamika Pendidikan Nasional}

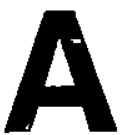

manah untuk menyelenggarakan beragam pendidikan yang dipertukan dalam mengisi kemerdekaan dan memerdekakan kehidupan berbangsa tersurat dalam alinea empat Pembukaan UUD 1945, yaitu: "mencerdaskan kehidupan bangsa", serta pada Pasal 31 UUD 1945, bahwa: (1) Tiap-tiap warga negara berhak mendapat pengajaran, (2) Pemerintah mengusahakan penyelenggaraan satu sistem pengajaran nasional yang diatur dalam Uridang-Undang. Pengertian "pengajaran" dalam Pasal 31 UUD 1945 identik dengan pengertian "pendidikan" yang dikenal sekarang. Istilah "pengajaran" di masa lalu juga melekat pada nama Departemen Pengajaran yang sekarang menjadi Departemen Pendidikan Nasional. Sehingga tafsir hukum dari pasal ini adalah: ayat pertama menunjukkan bahwa pemerintah dan bangsa Indonesia menghormati dan melindungi hak asasi individu yang berkedudukan sebagai warga negara untuk mendapatkan pengajaran. Ayat dua menunjukkan bahwa pemerintah dalam alam kemerdekaan akan mewujudkan kewajiban melindungi hak asasi untuk mendapatkan pendidikan bagi warga negaranya, dengan menyelenggarakan satu sistem pendidikan nasional.

Pada muaranya "pendidikan adalah suatu proses di mana suatu bangsa mempersiapkan generasi mudanya untuk menjalankan kehidupan dan untuk memenuhi tujuan hidup secara efektif dan efisien. Pendidikan, pengajaran, dan pelatihan, bergerak di antara empat nilai. Pertama, nilai pragmatis untuk mempertahankan kehidupan sehari-hari. Kedua, nilai personal untuk bertumbuh menjadi dewasa, berinisiatif, kreatif, bertanggungjawab, dan karenanya mandiri. Ketiga, nilai sosial-emosional untuk menjadi berdaya dan merdeka lewat proses saling memberdayakan dan saling memerdekakan. Keempat, nilai moral-spiritual untuk mengalami pertobatan dan pencerahan budi dan jiwa/rohani. Oleh karena itu implementasi pengajaran dari amanah 
UUD 1945 oleh pemerintah dijabarkan dalam tujuan pendidikan nasional (UU No. 2 Tahun 1989), yaitu: mencerdaskan kehidupan bangsa dan mengembangkan manusia Indonesia seutuhnya, yaitu manusia yang beriman dan bertaqwa terhadap Tuhan Yang Maha Esa dan berbudi luhur, memiliki pengetahuan dan ketrampilan, kesehatan jasmani dan rohani, kepribadian yang mantap dan mandiri serta rasa tanggungjawab kemasyarakatan dan kebangsaan.

Di Indonesia, wacana pendidikan Islam juga turut menghiasi perkembangan dan pengembangan pendidikán nasional. Pengertian pendidikan dengan seluruh totalitasnya dalam konteks Islam inheren dalam konotasi istilah "tarbiyah", "ta'lim" dan "ta'dib" yang harus dipahami secara bersamasama. Ketiga istilah itu mengandung makna yang amat dalam menyangkut manusia dan masyarakat serta lingkungan dalam hubungannya derigan Tuhan serta kaitan satu sama lain. Istilah-istilah itu pula sekaligus menjelaskan ruang lingkup pendidikan Islam; "informal", "formal" dan "nonformal".

Sejarah pendidikan Indonesia sesungguhnya sangat diwarnai oleh peran maupun pengalaman umat Islam dalam menampilkan pendidikannya. Kehadiran organisasi-organisasi gerakan Islam seperti Muhammadiyah dan NU selalu menempatkan pendidikan sebagai basis sekaligus motor penggeraknya. Berbagai model, jenis dan jenjang pendidikan yang didirikan dan dikelola oleh organisasi-organisasi Islam sebelum dan sesudah Indonesia merdeka telah memberi andil bagi kehadiran pendidikan nasional. Terlepas dari segala kelemahan dan kekurangannya, kehadiran lembaga-lembaga pendidikan yang diselenggarakan oleh umat Islam Indonesia boleh dikatakan merupakan wujud nyata dari apa yang sekarang diharapkan sebagai usaha menuju "pendidikan berbasis masya- rakat" (coimmunity base education).

Periyelenggaraan dan pengelolaan sekolah-sekolah dari tingkat sekolah dasar hingga perguruan tinggi yang diselenggarakan pemerintah (negeri) bersifat departemental, meskipun pada ujungnya otoritas kurikulum tetap dalam genggaman Departemen Pendidikan Nasional. Semisal, sekolah-sekolah di bawah Diknas memakai nomenklatur: sekolah dasar (SD), sekolah lanjutan pertama (SLP), dan sekolah menengah umum (SMU); dan sekolah-sekolah di bawah Depag menggunakan nomenklatur: madrasah lbtidaiyah, madrasah Tsanawiyah, dan madrasah 'Aliyah. Di tingkat perguruan tinggi lebih beragam, Diknas memiliki universitas "umum" semisal Universitas Gajah Mada (UGM), Universitas Indonesia (UI), dan lain-lain, serta beberapa universitas negeri ekspansi dari IKIP Negeri. Depag memiliki STAIN dan IAIN. Departemen Pertahanan dan Keamanan memiliki AKABRI, Departemen Perindustrian dan Perdagangan memiliki Akademi Teknologi Kulit (ATK), Departemen Dalam Negeri memiliki Sekolah Tinggi llmu Pemerintahan Dalam Negeri (STIPDN), Departemen Keuangan memiliki Sekolah Tinggi Akuntansi Negara (STAN).

Dinamika menarik ada dalam perkembangan dan pengembangan STAIN dan IAIN. Pada awal perkembangannya, muncul kesadaran bahwa agama perlu diajarkan secara luas pada masyarakat, maka dibukalah fakultas/jurusan tarbiyah. Pada tahap selanjutnya ketika muncul kesadaran perlunya sosialisasi ilmu agama pada masyarakat, maka dibuka fakultas/jurusan dakwah; dan untuk dapat menjawab berbagai persoalan fiqiyah dibukalah fakultas/ jurusan adab dan syariah; dan selanjutnya ketika diperlukan pengembangan pemikiran dari Qur'an dan Hadits dibukalah fakultas/ jurusan ushuludin. 
Beberapa tantangan dan masalah bagi STAIN/AIN adalah; Pertama, pengembangan IAIN Jakarta dan IAIN Yogyakarta sebagai "IAIN Pembina" yang bertugas membina dan mengembangkan IAIN dan STAIN lainnya. Kedua IAIN ini akan dikembangkan dengan konsep dasar "IAIN dengan mandat yang diperluas" (wider mandate). Dengan konsep ini, IAIN mempunyai mandat tidak hanya dalam bidang agama, melainkan juga dalam bidang-bidang ilmu sosial, humaniora, dan ilmu-ilmu alam/eksakta. Dengan mandat yang lebih luas ini, maka upaya untuk mengintegrasikan "ilmu agama" dan "ilmu umum" dapat direalisasikan. Kedua, peningkatan otonomi IAIN. Dengan otonomi yang lebih besar, IAIN dapat mengembangkan dirinya secara lebih maksimal, baik dalam bidang ilmiah-akademik maupun dalam manajemen dan keuangan. Ketiga, peningkatan akuntabilitas IAIN dari segi kelembagaan dan akademis, sehingga kelembagaan IAIN lebih kokoh dan alumninya juga lebih profesional, baik dalam ilmu agama (yang menjadi basic-nya) maupun dalam ilmu umum, serta keahlian dan ketrampilannya. Keempat, peningkatan kerja sama dengan perguruan tinggi lainnya baik di dalam maupun di luar negeri, guna menciptakan sinergi yang dapat mendorong akselerasi peningkatan mutu pendidikan IAIN.

Dinamika pendidikan "tinggi" nasional terus bergolak dan bergejolak di kalangan pergunan-perguruan tinggi di bawah Depag selaras dengan tuntutan perkembangan peradaban. Pro dan kontra hingga hari ini belum tertuntaskan dalam menyikapi wider mandate yang diberikan Diknas. Disatu pihak ada beberapa STAIN/AIN yang membuka jurusan-jurusan umum, dua di antaranya STAIN Surakarta yang membuka Jurusan Ekonomi Islam dengan tiga program studi: Keuangan dan Perbankan, Manajemen, dan Akuntansi, serta bekerja- sama dengan Universitas Negeri Yogyakarta (UNY) menyelenggarakan Jurusan Sastra Inggris; dan STAIN Malang yang membuka Jurusan Ekonomi Islam, Sastra Inggris, dan Psikologi. IAIN "Syarif Hidayatullah" Jakarta bertepatan dengan usianya yang ke- 45 atau lustrum ke- 9 telah berubah menjadi Universitas Islam Negeri "Syarif Hidayatullah" Jakarta. IAIN "Sunan Kalijaga" Yogyakarta yang diprediksikan segera menyusul, menjadi universitas ternyata masih harus menyelesaikan polemik di kalangan civitas akademikanya.

Berdasarkan surat Direktur Jenderal Pendidikan Tinggi Nomor: 2981/D/T/2001 yang selanjutnya diratifikasi dengan Surat Keputusan Direktur Jenderal Pembinaan Kelembagaan Agama Islam Nomor: E/282/ 2001, hanya tiga IAIN dan satu STAIN yang mendapatkan persetujuan pembukaan program studi umum dengan konsentrasi kegamaan. Masing-masing adalah: (1) IAIN Sunan Gunung Jati Bandung: Prodi Sosiologi, Konsentrasi Sosiologi Agama, (2) IAIN Sunan Ampel Surabaya: (a) Prodi Psikologi, Konsentrasi psikologi Agama, (b) Prodi llmu Komunikasi, Konsentrasi Komunikasi Keagamaan, (c) Prodi Sosiologi, Konsentrasi Sosiologi Agama, (3) IAIN Sultan Syarif Qasim Pekan Baru: Prodi Manajamen, Konsentrasi Manajemen Syariah, (4) STAIN Surakarta: Prodi Manajamen, Konsentrasi Manajemen Syariah.

STAIN Malang telah lebih dahulu mendapat persetujuan pembukaan prodi umum di lingkungannya, bahkan pada hari Sabtu, 13 Juli 2002 lalu telah berubah menjadi Universitas Islam Persahabatan Indonesia Sudan, setelah pemerintah Sudan mengajukan MoU dengan pemerintah Indonesia untuk membuka universitas. Dalam evaluasi kelayakan, STAIN Malang mengalahkan enam IAIN, setelah Depag memutuskan untuk memberikan penyelenggaraan universitas persahabatan Indonesia Sudan 
kepada STAIN/IAIN yang mengajukan diri untuk berubah menjadi universitas daripada membuka institusi pendidikan tinggi agama yang baru.

Dinamika perguruan tinggi "umum" di bawah Diknas lebih sensasional. Kompetitif-kompetensial mewarnai masing-masing perguruan tinggi dalam membangun mutu. Semisal, UGM menetapkan diri menjadi Research University. Pembukaan programprogram pasca sarjana yang semakin hari semakin ramai dan komplit-plit, baik pada PTN maupun PTS Merger merupakan fenomenologi menarik di aras perguruan tinggi swasta. Setelah dimulai oleh kelompok "Dian Nuswantara" Semarang, menyusul kemudian kelompok pendidikan tinggi di bawah Yayasan Dharma Bakti IImu Pengetahuan dan Teknologi Yogyakarta, ABAYO, STIEYO, STMIK DARMA BANGSA, merger menjadi Universitas Teknologi Yogyakarta. Pembukaan prodi-prodi Diploma di lingkungan Universitas "IKIP" Negeri Yogyakarta oleh Yayasan Pengembangan Pendidikan Ketrampilan dan Profesi (PPKP) yang menamakan diri sebagai "laskar pendidikan tanpa batas" menambah semaraknya dinamika pendidikan "tinggi" nasional.

Juga sekolah-sekolah dasar, madrasah ibtidaiyah, sekolah lanjutan pertama, madrasah tsanawiyah, sekolah menengah umum, dan madrasah aliyah baik negeri maupun swasta yang terus-menerus meningkat-ningkatkan kualitas dengan menyebut diri "Unggulan", semua itu adalah dinamika pendidikan nasional dalam koridor mencerdaskan kehidupan bangsa.

\section{Solusi Pendanaan Pendidikan pada Otonomi Daerah}

Perubahan konstelasi politik bangsa, dari yang tersentralistik selama tigapuluh dua tahun ke desentralistik untuk masa ke depan, tentunya memerlukan persiapan dan kesiapan matang. Beberapa permasalahan yang menonjol dalam sistem pendidikan nasional hingga hari ini, sebagaimana disinyalir Yahya Muhaimin dalam arahannya di depan "Konferensi Pendidikan Di Indonesia: Mengatasi Krisis Menuju Pembaruan", ketika menjabat Menteri Pendidikan Nasional, adalah: (1) masih rendahnya pemerataan memperoleh pendidikan; (2) masih rendahnya mutu dan relevansi pendidikan; dan (3) masih lemahnya manajemen pendidikan, disamping belum terwujudnya keunggulan ilmu pengetahuan dan teknologi di kalangan akademisi dan kemandirian. Ketimpangan pemerataan pendidikan juga tejadi antarwilayah geografis, yaitu antara perkotaan dan pedesaan, serta antara Kawasan Timur Indonesia (KTI) dan Kawasan Barat Indonesia (KBI), dan antartingkat pendapatan penduduk ataupun antargender.

Ketika UU No. 22/1999 tentang Pemerintah Daerah digagas, diskursus yang muncul kepermukaan ialah kebutuhan untuk menghadapi tantangan persaingan global. Dengan otonomi dan desentralisasi diharapkan semua komponen daerah lebih terpacu memberdayakan diri, mengembangkan mutu "kompetensial" sumber daya manusia, menumbuhkan prakarsa dan kreativitas, meningkatkan peran serta masyarakat, termasuk dalam meningkatkan sumber dana dan dalam penyelenggaraan pendidikan.

Implementasi otonomi daerah pada sistem pendidikan nasional, dalam arti authority mapping antara pusat dan daerah (kabupaten/kota) kurang lebih sebagai berikut: (1) kewenangan pemerintah pusat adalah kewenangan yang berkaitan dengan urusan yang menyangkut identitas dan integritas bangsa, persatuan dan kesatuan nasional, pelayanan yang mempunyai jangkauan nasional dan internasional, penentuan standar nasional ${ }_{i}$ pengendalian dan 
pemantauan mutu, dan urusan yang menyangkut kepentingan lintas propinsi. Kewenangan tersebut bersifat penetapan kebijakan, pedoman, norma standar, persyaratan, prosedur, dan pengaturan; (2) kewenangan kabupaten/kota adalah pada pelaksanaan, kecuali yang menurut PP No. 25/2000 menjadi wewenang propinsi dan yang diserahkan pada propinsi apabila kabupaten/kota tidak mampu melaksanakan; (3) koordinasi dengan dan dalam koridor negara kesatuan Republik Indonesia, maka pelaksanaan pendidikan di daerah tetap dalam kerangka sistem pendidikan nasional.

Hasil pantauan Tim Kerja Pusat Implementasi Otonomi Daerah beberapa waktu setelah pemberlakuan UU No. 22/1999 menemukan beberapa kejanggalan dan kecanggungan, di antaranya: (1) didapatkannya beberapa peraturan daerah dan keputusan kepala daerah yang tidak sejalan dengan kepentingan umum dan peraturan perundang-undangan, seperti: (a) persepsi yang kurang tepat tentang kewenangan, (b) pembentukan lembaga daerah yang tidak proporsional dengan kegiatan dan kewenangannya, (c) penempatan personil yang cenderung menjurus ke-daerahisme dan tidak berdasarkan profesionalisme, (d) tidak tercerminnya prioritas pembangunan pendidikan (SDM) dalam alokasi, (e) timbulnya kerancuan kewenangan antara pemerintah (pusat), propinsi, dan kabupaten/ kota; dan (2) belum lengkapnya fasilitas dari pemerintah pusat sesuai dengan Pasal 112 UU No. 2/1999, dalam hal ini termasuk aturan-aturan pelaksanaan dari UU dan PP yang berkaitan dengan otonomi daerah yang perlu disesuaikan.

Melihat misimplementasi tersebut Diknas segera menyusun juklak dan juknis bagi otonomi "pendidikan nasional" pada daerah-daerah, berupa: (1) pedoman yang berkaitan dengan Standar Pelayanan Mini- mal di bidang Dikdasmen, PLS, Pemuda dan Olahraga untuk digunakan oleh propinsi dalam menetapkan standar pelayanan minimal tingkat kabupaten/kota, dan pedoman pembiayaan pendidikan sebagai acuan pemerintah daerah dalam merencanakan dan mengalokasikan biaya untuk sekolah agar dapat dicapai hasil sesuai dengan standar yang telah ditetapkan; (2) pembaharuan kurikulum nasional yang dikembangkan berdasarkan kompetensi dasar yang meliputi kompetensi dasar per jenjang pendidikan dan per mata pelajaran yang meliputi standar kompetensi peserta didik dan standar materi pelajaran; (3) penyusunan rencana strategis (renstra), yaitu acuan dan pedoman bagi seluruh jajaran penyelenggara pendidikan, baik pemerintah maupun masyarakat, dalam merencanakan dan melaksanakan proses pembangunan nasional di bidang pendidikan lima tahun ke depan.

Misimplementasimerupakan gambaran faktual akan kekagetan daerah menerima kewenangan penuh dalam menata dirinya sendiri, mengingat selama ini kewenangan yang dimiliki daerah lebih bersifat "ninabubuk" dari pusat. Bagaimana halnya dengan harapan-harapan terhadap sistem pendidikan nasional memasuki otonomi daerah? Beberapa diskursus yang muncul ke permukaan menyarankan, pendidikan nasional hendaknya memiliki visi yang berorientasi pada demokrasi bangsa sehingga memungkinkan terjadinya proses pemberdayaan seluruh komponen masyarakat. Pendidikan nasional hendaknya memiliki misi agar tercapai partisipasi masyarakat secara menyelunuh sehingga secara mayoritas seluruh komponen bangsa yang ada dalam masyarakat menjadi terdidik. Substansi pendidikan dasar hendaknya mengacu pada pengembangan potensi dan kreativitas siswa dalam totalitasnya; substansi pendidikan nasional di jenjang.pendidikan 
menengah dan tinggi hendaknya membuka kemungkinan untuk terjadinya pengembangan individu secara vertikal, pada struktur keilmuan, dan horizontal pada keterkaitan dan relevansi antarbidang keilmuan. Pendidikan tinggi hendaknya jangan semata-mata hanya berorientasi pada penyiapan tenaga kerja. Tetapi lebih jauh dari itu harus memperkuat kemampuan dasar mahasiswa yang memungkinkan baginya untuk berkembang lebih jauh, baik sebagai individu, anggota masyarakat, maupun sebagai warga negara dalam konteks kehidupan yang global.

Penerapan otonomi daerah bidang pendidikan secara konseptual, dari rumusan visi, misi dan target-target jangka pendek, menengah, dan panjang dari sistem pendidikan nasional, insya Allah, telah siap. Selanjutnya yang perlu dilihat adalah kesiapan otonomi "pendanaan" daerah. Dari hasil pantauan Tim Kerja Pusat Otonomi Daerah, sebagaimana diungkapkan di depan, daerah belum mengalokasikan pendanaan pendidikan dalam RAPBD; alhasil, banyak tenaga pengajar yang tertunda penggajiannya, banyak fasilitas-fasilitas pendidikan yang tidak teropname, yang ujung-ujungnya bila tidak ditemukan solusinya, bisa-bisa otonomi "pendidikan" daerah gagal total atau bahkan melumatkan "sistem" pendidikan nasional. Sementara studi intensif untuk menemukan problem solving otonomi "pendanaan" daerah belum nampak, pihak mana yang berwenang; Dinas Pendidikan dan Pengajaran (P\&P) beserta jajarannya (termasuk di dalamnya sekolahan), atau Pemerintah Daerah.

Membuka diskursus tentang otonomi "pendanaan" daerah ini, ada beberapa pemikiran sederhana yang insya Allah tidak terlalu melangit, yang permasalahan dan pemecahannya terletak pada kepemilikan kita terhadap spirit enterprenuership. Agar lebih sistematis, kita akan mencoba me- metakan antara kebutuhan pendanaan operasional pendidikan dan kiat self financing yang dapat dilakukan oleh daerah. Pendanaan operasional pendidikan yang harus otonomi Pemda meliputi: (1) penggajian dan pengembangan SDM Kantor Dinas dan tenaga pengajar (Guru) "negeri" di sekolahan-sekolahan SD, SLTA, dan SMU; serta penggajian dan pengembangan SDM Kantor Kopertis dan tenaga akademik (Dosen) "negeri" disemua perguruan tinggi baik negeri maupun swasta; (2) maintenance dan pembangunan sarana dan prasarana (aset) Depniknas Daerah.

Penulis mohon maaf belum bisa menyajikan mata anggaran dan kebutuhan anggaran per Dinas per daerah, oleh karena dataBase untuk itu masih sulit didapatkan, akan tetapi menurut penulis ada tiga diskursus yang dapat dikembangkan pada daerah. Pertama, hal yang lebih perlu ditingkatkan antara jajaran Dinas P\&P dengan Pemda adalah hubungan fungsional. Keduanya perlu duduk bersama untuk menyusun serangkaian rencana strategis tentang pertumbuhan ekonomi daerah dan kebutuhan SDM-nya.

Hubungan simbiosa mutualisma keduanya perlu terus dan terus dibangun, antara sekolahan dari unsur Dinas P\&P dan Pemda memiliki tanggungjawab bersama merancang industrial daerah, dari input (eksplorasi sumber daya daerah), proses (ketersediaan SDM dan pendanaan) oleh dan dari putra-putri daerah, dan output (pemasaran dan penjualan hasil industrial) untuk seluruh bangsa dan dunia. Sumber daya daerah mencakup potensi sumber daya alam dan potensi "pesona" daerah lainnya. Semisal, Kabupaten Lamongan di bawah kepemimpinan Bupati Masfuk, mengembangkan potensi "pesona" daerah Soto Lamongannya. Masyarakat diberdayakan untuk membuka warung-warung soto di sepanjang kabupaten lamongan 
dari ujung ke ujung. Jogjakarta mempunyai "pesona" erotisme budaya, oleh karenanya Jogjakarta layak mentargetkan "Jogjakarta menuju dunia dan dunia menuju Jogjakarta" dalam "Jogja Never Ending Asia". Artinya bahwa Jogjakarta dapat melakukan eksplorasi industri pariwisatanya dari erotisme budaya yang dimilikinya, bahkan jika perlu dicari alternatif kemasan pariwisata yang komplit-plit ada di Jogjakarta. Semisal, mengingat Jogjakarta adalah Kota Pendidikan, maka perlu dilakukan studi tentang "Wisata Pendidikan", yang realisasinya diwujudkan dengan menginstruksikan kepada semua sekolahan dari SD hingga PT untuk membangun Museum Sekolah, paling tidak bagi sekolahan-sekolahan yang telah melegenda, seperti UGM, UII, SMU Padmanaba, dan lain-lain.

Kedua, Diknas P\&P perlu melakukan konsolidasi internal, menyeimbangkan pola pembinaan bagi sekolahan negeri dan swasta. Selama ini unsur kenegerian lembaga ataupun SDM selalu mendapatkan porsi hak yang lebih banyak dari swasta. Balancing dalam hal ini dimaksudkan untuk: (a) memberi ruang-gerak yang semakin kompetitif bagi sekolahan-sekolahan dalam membangun mutunya; (b) pada sekolahan/kampus swasta yang sudah establish, dalam kondisi sebagaimana saat ini, penggajian Guru/Dosen negeri yang berada di sekolahan/kampus tersebut dapat ditemukan solusinya dengan, untuk sementara, memperkecil subsidi penggajian atau bahkan menitipkan sementara penggajiannya pada institusi tersebut, sembari menunggu kesanggupan Pemda.

Ketiga, untuk menggelontor dana beasiswa dan peningkatan SDM, Pemda dapat membangun jalinan dan jaringan dengan badan-badan sosial, seperti: Dompet Dhuafa, Dompet Umul Quro', Bank Syariah, Bank Perkreditan Rakyat Syariah, dan Lembaga Keuangan Syariah "BMT" yang mengelola pendanaan maal; dengan menyediakan perangkat hukum bagi ruang gerak mereka dalam pengambilan zakat, infaq, dan shadaqah bagi pihak-pihak terkena kewajiban dan senang menghidupkan sunah.

\section{Penutup}

"Serba-Serbi" dimaksudkan untuk membuat kesan ringan terhadap tematik yang sebenamya cukup berat untuk pembahasan yang terbatas, juga untuk memberi kesan keberaneka-bahasan, meskipun tetap dalam satu koridor tematik.

Amanah konstitusi untuk mencerdaskan kehidupan bangsa, rasanya sudah sedemikian optimal kita lakukan, melalui dinamika penyelenggaraan pendidikan nasional, namun rasanya kita masih jalan ditempat ketika kita menengok peran serupa yang telah dimainkan negaranegara lain.

"Serba-Serbi" ditutup dengan Solusi Pendanaan Pendidikan Pada Otonomi Daerah, mengungkapkan fakta akan kekagetan daerah mengekspresikan UU No. 22/1999 serta sumbang saran untuk mencari sumber otonomi "pendanaan" daerah bagi keberlangsungan "amanah" pendidikan nasional. Wallahu a'lam.

\section{Referensi}

Al Qardhawi, Yusuf, 1980, Pendidikan Islam dan Madrasah Hasan al-Banna, terj. Prof. H. Bustani A. Gani dan Drs. Zainal Abidin, Bulan Bintang, Jakarta.

Azra, Azyumardi, 1999, Esei Esei Intelektual Muslim dan Pendidikan Islam, PT. Logos Wacana Ilmu, Jakarta, h. 3.

Azra, Azyumardi, 1999, Pendidikan Islam: Tradisi dan Modernisasi Menuju Milenium Baru, PT. Logos Wacana IImu, Jakarta, h. 4. 
Buchori, Mochtar, 1994, Pendidikan dalam Pembangunan, IKIP Muhammadiyah Jakarta-Press dan Tiara Wacana Yogya, Yogyakarta.

Buchori, Mochtar, 1994, IImu Pendidikan dan Praktek Pendidikan, IKIP Muhammadiyah Jakarta-Press dan Tiara Wacana Yogya, Yogyakarta.

Darmaningtyas, 1999, Pendidikan pada dan Setelah Krisis, Pustaka Pelajar, Yogyakarta.

Drucker, Peter F, 1985, Inovation and Enterprenuership, London: Heinemann.

Fadjar, Malik A., 1999, Reorientasi Pendidikan Islam, Yayasan Pendidikan FAJAR DUNIA, Jawa Timur, h. xiii.

Fagerlind, Ingemar and SAHA, Lawrence J., 1983, Education and National Development, Oxford, New York, tsc.: Pergamon Pers.

Freire, Paulo, Illich, Ivan dan FROMM, Erich, 1999, Menggugat Pendidikan, Alih Bahasa Omi Intan Naomi, Pustaka Pelajar, Yogyakarta.
Harefa, Andrias, 2001, Pembelajaran Di Era Serba Otonomi, Penerbit Buku Kompas, Jakarta, h. v.

Jalal, Fasli dan Supriadi, Dedi, 2001, Reformasi Pendidikan Dalam Konteks Otonomi Daerah, Adicita, Yogyakarta, h. v, 369, xxxii.

Nawawi, Hadari H. dan Martini, Mimi H. 1994, Kebijakan Pendidikan di Indonesia Ditinjau Dari Sudut Hukum, Gajah Mada University Press, Yogyakarta, h. 41-42. Suyanto dan Hisyam, Djihad, 2000, Refleksi dan Reformasi Pendidikan Di Indonesia Memasuki Milenium III, Adi Cita, Yogyakarta.

Rahardjo, Dawam, 1997, Keluar Dari Kemelut Pendidikan Nasional, PT. intermasa, Jakarta.

Tampubolon, Daulat P., 2001, Perguruan Tinggi Bermutu, Paradigma Baru Manajemen Pendidikan Tinggi Menghadapi Tantangan Abad ke-21, PT. Gramedia Pustaka Utama, Jakarta. 